\title{
Superhombre y hombre total 1
}

\author{
Surhomme et homme total
}

\author{
Gérard LEBRUN
}

Recibido: $17 / 12 / 2009$

Aceptado: 21/01/2010

\footnotetext{
1 Nota preliminar: El presente artículo, traducido al hilo de la polémica surgida en el seminario dirigido por Carlos Fernández Liria Técnica, nihilismo y capitalismo (Master de Estudios Avanzados en Filosofía de la U.C.M.) fue originalmente publicado (1978) en Brasil (Separata de Manuscrito. Vol. II. $\mathrm{n}^{\circ}$ 1. Campinas-São Paolo) y, posteriormente, (2002) en Francia (Cahiers Philosophiques, "Nietzsche", no 90, http://www.cndp.fr/revuecphil/ ).

Todas las referencias bibliográficas aportadas por Gérard Lebrun en el presente artículo corresponden a ediciones francesas: sea de obras extranjeras traducidas al francés, sea de obras francesas en su edición original. Por este motivo, se ofrece al lector la siguiente relación de las obras disponibles en su traducción al castellano:

Castoriadis, C.: Experiencia del movimiento obrero, Barcelona, Tusquets, 1979.

Deleuze, G.: La lógica del sentido, Barcelona, Paidós, 2005.

Engels, F.: Dialéctica de la naturaleza, Barcelona, Crítica, 1979.

-Anti-Dühring: o la revolución de la ciencia de Eugenio Dühring (introducción al estudio del socialismo), Madrid, Ayuso, 1978.

-El origen de la familia, de la propiedad y del Estado: en relación con las investigaciones de L. H. Morgan, Madrid, Endymión, 1988.

Fichte, J. G.: El destino del hombre, Madrid, Espasa-Calpe, 1976.

Heidegger, M.: Nietzsche, Barcelona, Destino, 2000.

Kant, I.: "Idea de una historia universal en sentido cosmopolita", en Filosofía de la historia, México DF, Fondo de Cultura Económica, 1953.

Lenin, V.: Dos tácticas de la social-democracia, Moscú, Ediciones en lenguas extranjeras, 1947.

Marx, K.: Lineas fundamentales de la crítica de la economía politica: "Grundrisse", Barcelona, Grijalbo, 1978.

-La ideología alemana y otros escritos filosóficos, Madrid, Losada, 2005.

-Manuscritos económico-filosóficos de 1844, Buenos Aires, Ediciones Colihue, 2004.
} 
«Nicht um die Erfinder von neuem Lärme: um die Erfinder von neuen Werten dreht sich die Welt: unbörbar dreht sie sich.» Zaratustra - Von großzen Ereignissen*

No propondremos aquí un nuevo comentario de la idea de Superhombre. Al igual que otros conceptos de Nietzsche, éste, en efecto, se presta a un uso distinto del comentario tradicional: podemos dejarlo operar. Así, sin tratar de bosquejar una nueva interpretación del Superhombre, intentaremos, ayudándonos de las indicaciones contenidas en la Voluntad de poder, hacer trabajar a la noción sobre un terreno bien delimitado: como analizador de una muestra de lo que Nietzsche llamaba «las ideas modernas». A la idea de Superhombre, no le pediremos por tanto más que una instrucción negativa y decepcionante. Aunque, al fin y al cabo, ¿tiene acaso la idea de Superhombre otro empleo en el Zaratustra? Más que como un mensaje de esperanza, el Superhombre aparece ahí como una lupa dirigida hacia la «decadencia».

¿Un tema ideológico reaccionario? A pesar de algunos textos ambiguos y de tantas críticas coléricas, no es tan evidente. Fue sin duda inevitable que el Superhombre haya terminado por cubrirse en nuestra imaginación de tristes eslóganes: «la raza de los señores», «el Reich que durará mil años». Sin embargo, si se consiente en regresar a las palabras de Nietzsche sin tomar el Horst Wessel Lied como ruido de fondo, nos daremos cuenta rápidamente de que los textos relativos al Superhombre deberían decepcionar al esteta que podría aún seducir al mito así como desarmar al alma bella y recelosa. ¿Qué encontramos en esos textos? Antes de nada, una parábola para un nuevo procedimiento de formación que no ha sido aún practicado nunca en la historia.

«Es necesario un contra-movimiento. Designo a este contra-movimiento en tanto que separación de un lujo excedentario de la humanidad: en ella, una especie más fuerte, un tipo más elevado, deben salir a la luz, teniendo unas condiciones de formación y de conservación distintas de las del hombre medio. Mi concepto, mi parábola de este tipo humano es, como se sabe, el término Superhombre ${ }^{2}$ ».

\footnotetext{
Nietzsche, F.: Obras completas de Federico Nietzsche, Buenos Aires, Aguilar, 1967 [El anticristo, Así habló Zaratustra, Consideraciones intempestivas, El Crepúsculo de los ídolos, Ecce homo, La gaya ciencia, Humano demasiado humano, La voluntad de poder, Schopenhauer como educador].

* "El mundo no gravita sobre los inventores de nuevos estruendos, sino sobre los inventores de nuevos valores. Y gravita en silencio". Nietzsche, De grandes acontecimientos, en Así habló Zaratustra. En alemán sin traducir en la edición francesa. $N$. del $T$.
}

2 Wille zur Macht, $\mathrm{n}^{\mathrm{o}} 866$. 


\section{Gestión de las fuerzas y planificación del movimiento}

El ascenso hacia el superhombre no puede ser más que la cría* sistemática de una «raza» cuyas dispersas muestras no habían surgido, hasta la fecha, más que del azar de las circunstancias ${ }^{3}$. La palabra Superhombre -y esto es importante- evoca primeramente la posibilidad de una forma totalmente distinta de Bildung, lejos de invitarnos a soñar con un «Hombre» según nuestros deseos. Este ideal [el sueño de un «hombre» según nuestros deseos] se encontraría aún inmerso en el canon de la educación moral, a la cual Nietzsche, precisamente, opone «la creación de circunstancias en las cuales unos hombres más fuertes son indispensables, unos hombres que, por su parte, necesitan una moral (preciso: una disciplina corporal y espiritual) que hace fuerte - en consecuencia, una moral que es poseída por ellos ${ }^{4}$ ».

Podríamos seguir a través de la obra de Nietzsche esta exigencia de una formación por fin consciente y voluntaria que pondría fin a la influencia del azar, del «milagro» de la educación. Ya en Schopenhauer como educador, Nietzsche muestra su deseo de que la humanidad «busque y realice las circunstancias que propiciarán el nacimiento de los grandes hombres, de los redentores». Y, un poco más tarde, opone a la educación milagrosa en la que todos creen aún, una educación natural, que sería apta para preservar científicamente las energías adquiridas así como para suscitar nuevas5. Este esquema, reconozcámoslo, es poco original y, a primera vista, contribuiría más bien a volver a arrojar a Nietzsche entre los teóricos del progreso o, por lo menos, entre los autores escatológicos. La idea de que por fin es posible salir de la pre-historia anárquica de las fuerzas para entrar en una era donde la humanidad ejercerá sobre estas fuerzas un dominio integral, es una idea que domina tanto la economía nietzscheana del poder como la economía marxiana de las fuerzas productivas, hasta tal punto que un paralelismo entre Nietzsche y los clásicos del marxismo sería, sobre este punto, instructivo. Nietzsche, por ejemplo, indica que deberíamos poder sacar provecho del «excedente» (Ueberschutz) de fuerza, la capitalización de poder producto de siglos de ascesis. Esta ascesis -que fue desviada por el cristianismo- ha hecho posible una inmensa reserva de fuerzas para una nueva gestión que ejercerán los «legisladores» por venir6. Ahora bien,

\footnotetext{
* Dressage. Ver nota 48. N. del T.

3 «Este tipo de valor superior ya se ha visto a menudo; pero como un azar, una excepción, jamás como tipo querido.» (L'antechrist §3).

4 Wille zur Macht, n 973: «¿Dónde, hasta el momento, la planta hombre ha crecido de forma más esplendorosa?»

5 Troisième Consideration intempestive. Kröner. Bd. II, S.25I-2. Trad. G. Bianquis. Paris: Aubier, 1954.

6 «En general, cada cosa tiene tanto valor como lo que pagamos por ella. Sin embargo, esta regla no se cumple para el individuo aislado; sus grandes aptitudes no se relacionan con lo que él ha sacrificado, sufrido, realizado por sí mismo. Pero si se le echa un vistazo a su ascendencia, descubrimos un
} 
Marx y Engels describen igualmente en términos de gestión de las fuerzas el movimiento histórico de Occidente $-\mathrm{y}$ encontramos también en ellos la oposición entre el desorden pasado y la planificación que se encuentra de ahora en adelante a nuestro alcance. Ninguna sociedad, en el pasado, ha sabido afrontar el problema del crecimiento económico: «hasta ahora, todas las formas de sociedad han sucumbido al desarrollo de la riqueza, o lo que es lo mismo, al desarrollo de las fuerzas productivas $7 . »$ La revolución socialista será por tanto también (parece incluso que quizá será sobretodo) el reemplazo del crecimiento caótico por el crecimiento plenamente controlado, -el advenimiento del primer modo de producción que se ajuste al inmenso crecimiento de la productividad, ante el cual el capitalismo se encontrará cada vez más como un «brujo impotente» para controlar las fuerzas que él mismo ha conjurado. En una página sobrecogedora, Engels llega incluso a describir el paso al socialismo como una honesta e indispensable entrega de poderes que podría cumplirse -si tomamos estas líneas al pie de la letra- sin demasiados conflictos ${ }^{8}$. Un «compromiso histórico», como se dice, más lapidariamente, en italiano.

Vemos así que no sería descabellado comparar en este punto la «legislación» nietzscheana y el socialismo: la formación por fin racional de los individuos y el crecimiento por fin sustraído del azar tienen al menos en común el hecho de ser dos modos de reempleo de fuerzas, que pondrán fin al despilfarro de las mismas. Pero intuimos que el parecido se acaba rápido. Y es que, para Nietzsche, igual que «nuestros sociólogos», igual que «Herr Spencer», «nuestros socialistas son unos decadentes ${ }^{9} \gg$. Si la nueva socialización y el desarrollo sin dificultades de la productividad deben transformar el destino de los hombres, eso será, piensa Nietzsche, en el sentido de una creciente desorganización de las fuerzas, de una caída de poder, que los «socialistas», por su parte, presentan como una situación inmejorable. Ahora bien, este desenlace no sería en realidad más que un «fenómeno regresivo del mayor estilo», «nada más que un envilecimiento del tipo humano», a no ser que propiciara un «contra-movimiento»: la llegada del Superhombre.

enorme ahorro y capitalización de fuerza por medio de renuncias, de luchas, de trabajos, de esfuerzos de todo tipo. El gran hombre es tal por todo lo que ha costado que sea grande, y no porque sea un milagro, un don del cielo y del "azar": La "herencia" es un concepto falso. Los ascendentes son los responsables de aquel que es único.» Wille zur Macht, $\mathrm{n}^{\circ} 969$. Ver $\mathrm{n}^{\circ} 898$.

7 Marx. Grundrisse. 1857-1858. Trad. R. Dangeville. Tome III. Paris: UGE, Éd. Anthropos, 1968. p. 60. 8 «La pretendida lucha por la vida toma entonces una forma tal que surge la necesidad de proteger los productos y las fuerzas de producción creadas por la sociedad burguesa y el capitalismo contra el efecto destructor y devastador de ese mismo régimen capitalista, retirándole a la clase capitalista dominante la dirección de la producción y de la repartición social, para la que ha quedado indispuesta, y entregándosela de nuevo a la masa de productores -esto es la revolución socialista.» Engels. La Dialectique de la nature. Éd. sociales, 1968. p. 318.

${ }^{9}$ Crépuscule del idoles. 337. 
Una vez que tengamos entre manos esta gestión total de la economía de la Tierra, cosa que ocurrirá inevitablemente, entonces la humanidad podrá encontrar su mejor sentido en tanto que maquinaria al servicio de esta economía: en tanto que un enorme engranaje de ruedas cada vez más finas, cada vez más sutilmente adaptadas, en tanto que un devenir-superfluo creciente de todos los elementos que dominan y mandan; en tanto que una totalidad de fuerzas enormes cuyos factores aislados representan fuerzas y valores mínimos ${ }^{10 .}$

Concedámosle a Engels que la anarquía de la producción social será reemplazada por la «organización social planificada consciente ${ }^{11}$ ». Admitamos incluso que la expoliación de la mayoría dará lugar a una nivelación de las condiciones. Pero, para convertirse en «maquinarias» benéficas, ¿cesarán las sociedades de ser un «caos de átomos»? Nietzsche predice que no. Lejos de favorecer realización alguna del ser humano, la organización planificada de la economía de la Tierra acentuará los rasgos de la era mercantil y, más bien, adelantará la llegada de ese «último hombre» que Zaratustra, al principio del libro, propone a la masa a modo de espantajo. ¿De dónde viene entonces el que los «socialistas» se cieguen acerca del sentido de su acción, sino del hecho de que ceden, ellos también, al espejismo del «optimismo económico»? Para ellos también, parece ir de suyo que el progreso de esa sociedad futura que estará en disposición de acomodarse al crecimiento ininterrumpido irá dirigido a una maximización de la cultura y de la calidad humana. Va de suyo, para Marx y Engels, que la civilización -sin comillas- está ligada a la «expansión constante» y al desarrollo continuo del tejido del mercado mundial: «la base del mercado mundial encierra la posibilidad del desarrollo universal del individuo ${ }^{12}$ 》. Va de suyo que «el sistema de explotación general de la naturaleza y del hombre» desembocará en la posibilidad de un perfeccionamiento humano ilimitado. Va de suyo que «la liberación de cada individuo en particular» está regida por la transformación de la historia en Weltgeschichte, ya que ésta pondrá al individuo «en relación práctica con la producción del mundo entero, incluida la producción intelectual 13 》. Por último, «está claro que la verdadera riqueza intelectual del individuo depende enteramente de la riqueza de sus relaciones reales» definidas de esa manera».

\footnotetext{
10 Wille zur Macht, $\mathrm{n}^{\circ} 866$.

11 Engels: L'Anti-Dühring. Éd. Sociales, 1977. p. 332.

12 Marx: Grundrisse. Op. cit., p. 63-64.

13 Engels, Marx: L'idéologie allemande. Éd. Sociales, 1968. p. 67.
} 


\section{EI «socialismo»: ¿subversión o relevo?}

Primera utilidad que ofrece la aplicación del analizador nietzscheano que prometíamos al principio: nos obliga a señalar estas dudosas evidencias. Nietzsche atrae nuestra atención sobre un a priori del marxismo que hay que distinguir muy bien de la tesis de la determinación de la superestructura por la infraestructura. En este contexto, dicha tesis no tiene demasiado interés -suponiendo que lo tenga en otros lugares ${ }^{14}$. De lo que queremos hablar es de la evaluación espontánea, que consiste en privilegiar el crecimiento económico en abstracto (ver la polémica que suscita, hace algunos años, el informe de Sicco Mansholt) y considerarlo incondicionalmente como la única matriz de la civilización. Esta opción aparece notoriamente en los elogios que Marx concede a la burguesía, «clase eminentemente revolucionaria», -elogios tan famosos que uno nunca cesa de preguntarse si el autor no había pecado de exceso de generosidad. ¿Quién no fue deslumbrado, en su infancia, por la página lírica del Manifiesto? «Es ella [la burguesía] la que ha demostrado primero lo que puede llevar a cabo la voluntad de los hombres»; es ella la que ha mezclado pueblos y condiciones sociales (ver la trata de Negros); incluso es ella, también ella, la que ha agotado «las literaturas nacionales y locales» en beneficio de una literatura universal, etc. 15 Todo esto, añade Marx, para desesperación de los reaccionarios... A riesgo de que parezca que tomamos por un instante el rol del reaccionario gruñón, osemos por lo menos preguntarnos de qué cultura superior podría el «tráfico universal» ser condición automática, -y cuál es ese «hombre total» (ese «superhombre» del porvenir que entreveía Kautsky) que no podrá surgir sino sobre la base del mercado mundial. Osemos preguntarnos si es necesario ver un gran paso hacia el florecimiento del hombre en el nacimiento de nuevas necesidades «que reclaman para su satisfacción productos de los climas y de los países más lejanos». La verdad es que yo nunca he tenido la impresión de que la tienda de alimentación Fauchon (place de la Madeleine), especializada en estos productos, fuera un santuario goethiano. Es verdad que, para Marx, «el máximo de necesidades» es signo de la más alta civilización, y que «cuanto más aumenta el nivel de cultura del hombre, más se encuentra éste en condiciones de disfrutar...16 ${ }_{\rangle}$Sería interesante remontarse a la genealogía de esta pamplina hedonista: sin tener en cuenta la imaginería de Épinal, terminaríamos quizá por reconocer a Marx, y ya no a Nietzsche, como un descendiente de Calicles. Contentémonos aquí con observar que todos los a priori que afloran en esta página del Manifiesto nos encarrilan hacia esta cuestión: ¿qué idea se hace el marxismo de la civilización para que el

\footnotetext{
14 Quiero decir: fuera de estudios monográficos (pensemos en algunos títulos de la literatura sociológica brasileña). Que la economía sea determinante en última instancia, es una idea a menudo fructuosa, bajo la condición de que se estipulen cuidadosamente los rasgos que determinan «lo económico» en una configuración determinada.

15 Ver L'idéologie allemande. Op. cit., p. 90.

16 Marx: Grundrisse. Tome II. Op. cit., p. 214.
} 
«reino de la libertad» que profetiza no pueda advenir más que en el eje del modo de producción capitalista, y para que la llegada del socialismo aparezca a veces incluso como el simple correctivo al que debe llamar tarde o temprano la revolución industrial? Pregunta que podría tomarse como la ocasión para abrir una investigación a través de aquellos textos marxistas que contienen lo que llamaremos, a falta de algo mejor, un «prejuicio de civilización». La dificultad de esa investigación no residiría en encontrar los ítems, sino más bien las rúbricas que los ordenarían, ya que las preguntas, así, afluyen sin orden. Citemos algunas, desordenadamente: ¿Es verdaderamente necesario considerar como una adquisición positiva el hecho de que «el celo por el trabajo impuesto por la severa disciplina del capital a las sucesivas generaciones se haya convertido en el bien común de la nueva humanidad ${ }^{17}$ »? ¿Cómo puede escribir Lenin en 1905 que «en países como Rusia, la clase obrera sufre menos por el capitalismo que por la insuficiencia de desarrollo del capitalismo», y que Rusia está por tanto «absolutamente interesa$d a$ en el desarrollo más amplio, más libre y más rápido del capitalismo» 18 ¿No resultan además sorprendentes los elogios que Lenin dirige a la disciplina de la manufactura en tanto que modo de Bildung, como resulta sorprendente el elogio que Engels hace de la centralización, primicia un poco inesperada de la desaparición del Estado19? Basta con abrir la investigación para ver cómo los indicios aumentan y encontrarse muy rápido en presencia de un fenómeno perturbador: si hay una cosa que los clásicos del marxismo no han problematizado jamás, es la relación de civilización del socialismo con el modo de producción que está abocado a abrirle el camino. En lo concerniente a este problema, es innegable que existe un «vacío» en el centro de la obra.

«Si la sociedad tal y como es, escribe Marx, no contuviera, en estado latente, las condiciones materiales de producción y de circulación propicias para una sociedad sin clases, todas las tentativas revolucionarias no serían más que don Quijotismo... $20_{\gg} \mathrm{Y}$ ya se sabe cuánto se burla el marxismo -fiel a Hegel en este punto- del «deber-ser» ideal de los utopistas, y se vanagloria de no prometer más una sociedad que brotaría de la anterior como Minerva de la frente de Zeus ${ }^{21}$. Pero llega un momento en que

17 Texto de los Grundrisse citado por Papaioannou: Les Marxistes. p. 211.

18 Lenin. Deux tactiques de la social-démocratie (1905). Ver el siguiente texto de Engels (1848) que cita M. Dangeville en su interesante prefacio a los textos sobre Le Parti de classe. I, p. 63 (Maspero): "Continuad pues combatiendo valientemente, graciosos señores del capital. Para el corto momento actual, aún os necesitamos; nos hace falta incluso, aquí y allá, vuestra dominación. Debéis barrer fuera de nuestra vía las formas patriarcales (precapitalistas); debéis centralizar; debéis transformar a las clases más o menos pudientes en auténticos proletarios, en reclutas para nosotros; debéis, con vuestras fábricas y vuestra red mercantil, proporcionarnos la base y los medios materiales necesarios para la emancipación del proletariado...»

19 Engels: La Guerre civile suisse (1874). Dangeille: Prefacio a Le parti de classe. Op. cit., p. 34.

20 Ver Papaioannou: Op. cit., p. 211.

21 El utopista, dice Plekhanov, partiendo de un concepto abstracto, «establece sin problemas con la mayor exactitud y con el detalle más minucioso cuáles deben ser (no sabemos cuándo, evidentemen- 
este realismo conduce a una discreción excesiva. En lo que se refiere a las «diferencias entre la futura sociedad no capitalista y la sociedad de hoy», remarca Engels, «el partido al que defiendo no propaga proyectos fijos listos para ser utilizados en tanto que tales 22 》: todo depende en cada caso de la observación del «proceso de desarrollo» de la sociedad considerada. Prudencia cuando menos loable. Pero, si es así, ¿no sería por ello aún más urgente determinar al menos lo que aceptaremos y lo que rechazaremos de la herencia, para que la subversión no sea en realidad un empalagoso relevo? Al refugiarnos tras el «proceso de desarrollo», no hacemos más que escamotear esta cuestión de principio -cuyas aplicaciones son rápidamente muy concretas. Y cuando nos contentamos con invocar el «paso ineluctable», damos pie a la sospecha de que la continuidad de una forma a la otra podría ser más profunda de lo que hace pensar el relato fanfarrón de las proezas del «hombre total» de mañana.

¿Cómo localizar los a priori de la civilización que el socialismo se arriesgaría a reemplazar? La pregunta no será formulada, el marxismo la evita y se queda satisfecho con esta inmensa preterición. El resultado es que, en numerosas páginas, la relación entre un modo de producción y el otro se parece a aquella que instituía Hegel -él muy explícitamente- entre el saber inmediato y el saber especulativo, o incluso entre el cristianismo y la filosofía ${ }^{23}$. Esta homología es sorprendente en los Grundrisse: dense cuenta de que ahí se habla constantemente de abolir las limitaciones, de levantar las barreras, de hacer saltar los bloqueos que obstaculizaban y ocultaban las relaciones de producción (que estaríamos tentados de llamar «representativas») para dejar libre el curso del crecimiento, o al destino de la humanidad. Como funciona de la misma manera que el paso de la religión al Saber hegeliano, el capitalismo tampoco dice algo distinto de lo que dice el socialismo, pero lo dice torpemente, absurdamente; a nosotros nos corresponde instaurar la verdadera sintaxis... Prosigamos la transposición: ¿para qué serviría preguntarse cuáles podrían ser los límites de validez del tipo industrial de desarrollo tomado como base y como norma? ¿Hegel nunca se ha inquietado por el hecho de que el cristianismo sea «el texto» de la filosofía? Las dos despreocupaciones se entre-responden. Pero uno se sorprende entonces un poco menos por el poco interés de algunos textos futurológicos de Marx: sirven simple y llanamente para esconder esta dificultad, que no debe ser evocada. En suma, cinismo aparte, estos textos anuncian maravillosamente el eslogan que Stalin tendrá la tranquila audacia de lanzar durante la Gran Purga: «La vida se ha vuelto mejor, la vida se ha vuelto más alegre...» Pero, más que hacer-

te, ni bajo qué circunstancias) por ejemplo las relaciones de propiedad entre los hombres. Como exige de sus adversarios un ideal detallado del porvenir, los hostiga con preguntas...» Essai sur le développement de la conception moniste de l'histoire. Ed. Françaises de Moscou, 1973. p. 285 sq.

22 Carta a Pease del 27 de enero de 1886. En Dangeville: Op. cit., p. 52.

23 Encontraremos en Engels (La Dialectique de la nature, Op. cit., p. 183) una descripción del capitalismo como reino de la inmediatez en el sentido hegeliano: incapacidad de prevenir «las consecuencias lejanas de las acciones», de planificar... 
nos una idea del horario de nuestros sobrinos (pesca por la mañana, formación por la tarde...), lo que nos interesa es saber en qué la actitud relativa al trabajo y a la industria habrá sido transformada, o bien cómo repercutirá la cooperación «voluntaria y consciente» sobre los que la practiquen. No una nueva utopía, pero al menos las grandes líneas de una prospectiva que nos indique en qué la Bildung habría cambiado de dirección, en qué habría mutación -Tomo aquí al lector como testigo: él no ha dejado de oír los relatos de viaje de «simpatizantes» que regresan de los países socialistas. Dejemos de lado al estalinista impenitente que se arriesga aún a hablar de la reeducación a través del trabajo, o el simpatizante «victoriano» que os asegura que, ahí, prostitución y homosexualidad han desaparecido como las ciáticas en la gruta de Lourdes; ignoremos los relatos de milagros y «maravillas». ¿No nos choca entonces lo insulso de la apología? La gente en la calle tiene un aire menos tenso, el paro no existe, las horas de trabajo están mejor distribuidas, las colonias de vacaciones del lago Balaton son espectaculares: «La vida se ha vuelto mejor, la vida se ha vuelto más alegre», al final siempre se vuelve a esto... Que se me entienda bien aquí: en la medida en que estos relatos son verídicos $-\mathrm{y}$ lo son la mayor parte de las veces-, los detalles que dan no son de ninguna manera insignificantes para el obrero paulista que pasa cuatro horas de su jornada en autobuses abarrotados o para el office-boy que no sabe qué significa la palabra «vacaciones». Sin embargo, simplemente observo que estos relatos me hacen pensar irresistiblemente en aquellos otros (de una banalidad chocante teniendo en cuenta que se había tratado de partir «al asalto del cielo») de los «bien pensantes» que regresan de una ciudad obrera modelo organizada por un «buen patrón». Y no vengáis ahora a replicar altivamente que el hombre dejará de estar encerrado en su particularidad, que estará prácticamente en condiciones de vivir plenamente el universal. Estas seguridades dejan de hielo: qué son más allá de una letanía neo-hegeliana, mientras continuéis evitando analizar lo que deberá ser o lo que debería comenzar a ser, a través del paso, la amplitud de la ruptura con el antiguo modo de vida. A falta de esto, las crónicas edificantes y las fantasiosas predicciones no sabrían impedir, a la larga, la aparición de la desconfianza: ¿nada esencial habría cambiado en los hábitos del hombre? Y la lucidez, ¿no se encontraría más bien del lado de Nietzsche?

\section{Dos territorios: desmitificación y crítica de las «interpretaciones»}

Bajo la apariencia de una digresión, no hemos cesado de comentar la previsión de Nietzsche: la gestión racional de la productividad no hará más que engendrar agentes utilitarios perfeccionados y precipitar la «mecanización» del hombre... Así, regresamos - comprendiendo mejor su alcance- a la condenación del «optimismo económico» y a la puesta en guardia de Nietzsche contra las ilusiones «modernas» 
acerca de los efectos de un crecimiento económico que sería controlado por la razón, puesta al servicio del universal. Sin duda, esta vía es desde ahora «totalmente previsible». Pero no encontraremos nada más, a su termino, que «una especie de estancación (nivel-Stillstands) del hombre».

Lo que yo combato, es el optimismo económico, como si, con los gastos crecientes de todos, debiera necesariamente crecer también el beneficio de todos. Lo contrario me parece más bien ser el caso: los gastos de todos se saldan en un déficit total; el ser humano se envilece; de modo que ya no se sabe a qué fin ha podido servir este enorme proceso...

No obstante, resultará inútil poner en paralelo estas dos prospectivas -y también injusto con Marx. Es demasiado fácil señalar que Nietzsche fue -sin esfuerzomejor profeta que él en cuanto al porvenir de Occidente. Acordado esto, hemos de reconocer que, en realidad, la problemática de Marx no lo comprometía con una prospectiva a largo plazo. Su objetivo era construir un modelo para una configuración económica y tecnológica dada de manera que fuera posible, aunque secundariamente, una previsión de sus recursos y de sus desenlaces históricos (los análisis del Sr. Balibar sobre esta cuestión son altamente sugestivos y convincentes). Si aceptamos esta delimitación temática estaremos en mejor disposición para mostrar el verdadero mérito de Marx: haber comprendido que el discurso hegeliano no podía aplicarse al siglo XIX tal y como se presentaba, -que la economía de Hegel estaba más próxima a la de los griegos que a la de Adam Smith, y que era necesario por tanto retomar de arriba abajo el análisis de la «sociedad civil». Se comprende también mejor su violencia, a menudo injusta con sus escritos, pero perfectamente fundada contra Hegel: era irrisorio hacer que la sociedad civil se sobrepasara discursivamente en el Estado, -señalando de paso, a modo de interés informativo, el nacimiento de un nuevo tipo de colonialismo, -fenómenos todos a los cuales la filosofía no otorgaba más importancia de la que merecen los avatares del mal infinito, que suscita por principio la ilimitación inherente a la actividad económica. Si hay un «retorno» del hegelianismo en Marx, es en ese proyecto de describir de cerca el crecimiento mandando a paseo las decisiones ontológicas hegelianas y sin dejarse fascinar, como Hegel, por el tema griego del Péras -de tal modo que se divisen en ella las condiciones de un infinito positivo en el sentido hegeliano 24 .

Por lo tanto, sería ilegítimo reprocharle a Marx aquello de lo que parecíamos estar quejándonos anteriormente: puesto que la tarea que se marcó era constituir la fisiología del modo de crecimiento que tenía frente a sus ojos, no tenía porqué interrogarse acerca de la posible relación entre la sociedad que él anunciaba y la «socie-

\footnotetext{
24 Para este punto, reenviamos al sugestivo artículo del Sr. Giannotti, J.: O Ardil do Trabalho. Sao Paulo: Cadernos do Cebrap, 1973.
} 
dad natural» que la preparaba. No era «el lugar para hablar de eso», como le gusta decir a Descartes a los objetantes. Lo importante era describir el funcionamiento del modo de producción presente con el objeto de mostrar que no tenía nada que ver con «la producción de la riqueza en sí» y de estipular la "particular limitación que le afecta». Si circunscribimos así el proyecto de Marx, convendremos que sería totalmente vano esperar de su obra una relativización de la cultura occidental o incluso una investigación crítica de sus ideales. Si el marxismo es una conceptualización original del doble desarrollo de una estrategia política, ¿por qué sorprenderse, por ejemplo, de que Marx y Engels fueran tan eurocentristas como el Hegel de la Filosofía de la historia? Nada en su proyecto les llevaba a tematizar la «civilización europea».

No se encuentran en Marx huellas de una crítica de la civilización, de una crítica de los «ideales». Quizás podría pensarse que esta afirmación es una locura, pero me gustaría que se me opusieran textos que la contravinieran. A título de ejercicio, tomo la página de los Grundrisse en la que Marx muestra su irritación fruto de la lectura de los socialistas franceses que pretenden poner en práctica las ideas burguesas de «libertad»y de «igualdad», sin sospechar que éstas, en realidad, no son más que «imágenes reflejadas de nuestra realidad presente». En esta página, parece que Marx la toma contra los ideales mismos de «libertad» y de «igualdad». Pero miremos un poco mejor. ¿Qué pretende probar, cuando afirma que «el valor de cambio, y mejor aún el sistema monetario, constituyen de hecho el fundamento de la igualdad y la libertad $25_{\Downarrow}$ ? Que el sujeto cambista no es ni mucho menos «el individuo libre» del que nos hablan los economistas y los ideólogos, sino, al contrario, un individuo cuya «naturaleza inmediata» está ya condicionada por un determinado estado de las relaciones de producción.

El individuo no tiene una existencia productiva más que a través del valor de cambio, lo cual implica la negación de su existencia natural; todo esto presupone la división del trabajo, en la que los hombres tienen relaciones de todo punto diferentes de las de simples cambistas, etc. Esta presuposición no se deriva por tanto de la voluntad ni de la naturaleza inmediata del individuo: es histórica, y el individuo se encuentra ubicado de antemano en unas condiciones determinadas por la sociedad.

Se entiende entonces en qué consiste el error de los socialistas ingenuos que toman la «libertad» y la «igualdad» del 89 como valores eternos. Este error no viene del hecho de que estas ideas estén fechadas históricamente, sino del hecho de que esta inscripción histórica se deba ella misma a una presuposición (a saber, el rol de fundamento que desempeña el valor de cambio) -presuposición que basta poner de manifiesto para anular la imagen idílica de individuos intercambiando «libremente»

25 Marx: Grundrisse. Tomo II. Op. cit., p.17-18. 
sus productos.Podemos preguntarnos ahora si, a lo largo de este análisis, ha sido puesto en cuestión un solo instante el ideal de «individuo libre». En absoluto. Comprender como momentos o productos «históricos» las falsas categorías «naturales» del sentido común es al mismo tiempo mostrar que éstas, en realidad, provienen de una configuración determinante y acusar su fragilidad, así como la inevitable impostura de los valores que se injertan sobre ellas. La «libertad», su «libertad», es el reflejo de la situación determinada del individuo en el sistema productivo. «Sabemos que en las profundidades se desarrollan movimientos completamente distintos, donde desaparece esta aparente igualdad y libertad de los individuos». Marx nos muestra así cómo el sistema falsifica, desde el principio, el sentido de las palabras normativas, y la ingenuidad que constituiría retomarlas sin precaución ${ }^{26}$. Sin embargo, no trata de analizar por qué, en la superficie, las palabras «libertad»e «igualdad» fueron marcadas de esta manera. Falsos [mensongères] valores, de acuerdo. ¿Pero por qué esas falsedades [mensonges]? ¿Por qué esos valores? Para decidirlo, sería necesario detenerse en el nivel de su sentido aparente, preguntarse si no hay también una mistificación en el corazón de estos mismos valores tal y como son expresados, y no solamente en el hecho de que hayan sido falsificados. La desmitificación marxista muestra en qué sentido los valores burgueses ocultan lo contrario de lo que anuncian; pero no muestra en qué sentido son fariseos y lo seguirían siendo incluso si no fueran falsos [mensongères]. Este sería el objeto de una investigación diferente: la crítica de los ideales, precisamente. No resultará sorprendente entonces si, remontándonos a antes de la operación de desmitificación, acabamos encontrando una «interpretación» que resiste a toda desmitificación: la norma ideal del individuo «perfectamente libre». Así, en nombre de esta «interpretación» indiscutida, Engels describe los maleficios del intercambio, desde aquel tiempo feliz en que «los iroqueses eran dueños de su propia producción 27 ». No concluiremos de esto que la desmitificación llega menos lejos que el desciframiento de interpretaciones, sino más bien que responde a un objetivo distinto: una cosa es preguntarse cómo son determinados los individuos en el interior de un modo de producción, y otra cosa es tratar de saber cómo queda marcada una palabra en el interior de un área de civilización.

Si Marx puede ser considerado como un filósofo de la Historia tan poco como Nietzsche, es por tanto de forma bien diferente. Marx niega haber querido extraer «leyes de la Historia»; no tiene más que sarcasmos para la diosa «Historia». Ocurre que el terreno sobre el que opera es la naturaleza interior a las situaciones históricas. Se encuentra cómodo donde reencuentra el juego de constricciones modalizan-

\footnotetext{
26 Marx, en 1864, a propósito de la Declaración de principios de la Internacional: «Se me impuso introducir en el preámbulo de los estatutos dos frases acerca de los Deberes y los Derechos, la Moral y la Justicia. Pero las coloqué de forma que esto no pueda hacer mal.»

27 Engels: L'origine de la familla, de la propriété et de l'État. Éd. Sociales, 1954. p. 105.
} 
tes que limitan el funcionamiento de un sistema y especifican el comportamiento de los agentes sociales. Pero ¿para qué sirve esta herramienta cuando se trata, por ejemplo, de redactar la tabla de valores para los cuales una formación social es receptiva, frente a aquellos contra los que está inmunizada? Nos encontramos entonces en otro territorio intra-histórico, cuya inteligibilidad ya no es formulable en «tendencias» y en «leyes». O mejor dicho, en un universo simbólico donde un método propio de la crítica de documentos y de la filología es más eficaz que el cuadro de las «presuposiciones» y de las «determinaciones». Aquí, es Nietzsche quien abre pistas inesperadas y fecundas; es Max Weber (y no Engels) quien nos hace entrever la especificidad de una religión. Si entendemos por ideología la red de modulaciones, y ya no de constricciones determinantes, que asignan las opciones y las interpretaciones de un grupo social cualquiera, hay que reconocer que el marxismo no aporta apenas lugares propios para hacer avanzar un saber acerca de las ideologías - mientras que la indexación en la «voluntad de poder» de conceptos, de motivaciones o de ritos aporta al menos elementos de una conceptualización original. Indicio, considerable indicio, de que decididamente no hubo para el marxismo una problemática de la civilización 28 .

He aquí porqué no sería serio establecer un paralelismo entre el advenimiento del «hombre total» y el ascenso hacia el superhombre -medir por el mismo rasero la «perspicacia» futurológica de Marx y de Nietzsche o pretender hacerlas entrar dentro del mismo palmarés, como si cada uno hubiera propuesto escolarmente $s u$ versión histórica. El interés de Nietzsche es más bien ofrecer una tópica que se encuentra ausente en el marxismo - una tópica que puede ser interesante, además, aplicar al marxismo para determinar mejor los presupuestos filosóficos que éste ha podido vehicular o asumir. Consideremos por ejemplo la simple convicción de que la fuerza ciega de la economía pueda someterse un día a la razón humana: no nos costará encontrar, en la Filosofía de la historia de Hegel, temas homólogos a éste -lo que sin embargo no significa que Marx haya tomado lisa y llanamente el relevo de Hegel... Otro ejemplo que me sugieren las líneas siguientes:

Empujadas por su insaciable avidez (las clases dirigentes) ampliarán sus usurpaciones de generación en generación y no dirán jamás basta hasta que, finalmente, la opresión alcance su apogeo y se vuelva absolutamente insoportable, de forma que la desesperación dé a los oprimidos la fuerza que no ha podido darles su coraje, anonadado desde hace siglos. Entonces no tolerarán más que haya en su seno cualquier individuo que no se contente con ser y mantenerse semejante a todos...

28 Remitimos al análisis que hace Catoriadis de la abstracción del concepto de «clase» definido en referencia a las relaciones de producción. Expérience du mouvement ouvrier. UGE, 1973. p. 54 sq. 
Estas líneas son de Fichte29. Y convendremos que algo de este esquema ha pasado al marxismo. Sin embargo, guardémonos por encima de todo de concluir que Marx era neo-fichteano. Esta afirmación resultaría vana, como resultaría vana toda pretensión de poner a Marx en relación con los post-kantianos al nivel de los conceptos y de las tesis ${ }^{30}$. En cambio, elaborar la relación de orientaciones o incluso de «tics» hegelianos con los que Marx se acomoda sí sería un trabajo provechoso de desciframiento de interpretaciones. Ejemplos de esta posible tópica: ¿qué impacto tiene, en el Capital, el tema del «mal infinito»? ¿Qué importancia tiene para Marx la oposición (que «va de suyo») «libertad/necesidad ciega»? ¿Cómo es retomada y reinvertida la imagen hegeliana de ciclo en los esquemas de la reproducción? Y, de forma más general, ¿hasta qué punto el reempleo de una imagen o de un tema hegeliano contribuye (excluyendo toda «coquetería retórica») a desviar el análisis? Esta investigación no sería en ningún caso competencia de un macro-análisis de los conceptos, tal y como lo practican los historiadores de la filosofía: no puede competer más que a la «filología» 31 . Si existe la posibilidad de descubrir a un Marx hegeliano, es por lo menos en la misma profundidad en que existe un Descartes aristotélico -en un basamento pre-doctrinal y a menudo pre-conceptual. Y es solamente en este nivel donde puede resultar interesante la pregunta que hacía, de forma algo abstracta, al principio: ¿es tan evidente el hecho de que el desarrollo de las fuerzas productivas, sea cual sea la manera en que son administradas, sea un modo seguro de detener el Entmenschung del que habla Nietzsche?

Esta convicción ¿no indicaría más bien que el marxismo, «último gran avatar del mito racionalista de Occidente... conserva lo esencial del universo racionalistaburgués en el nivel más profundo 32 \? Es en relación con esta cuestión que puede

\footnotetext{
29 Fichte: La Destination de l'homme. Trad. J. Molitor. Éd. Montaigne, 1942. p. 227.

30 Operar sobre las tesis filosóficas es, por ejemplo, pretender hacer la partición entre lo que había de utilizable para Marx en la dialéctica hegeliana y lo que había de «metafísico» -y uno de los grandes méritos del Sr. Althusser es haber mostrado la inanidad de tales ejercicios. Como ha dicho el Sr. Molino en su notable artículo: «Critique sémiologique de l'idéologie», Marx no ha relevado nada de la filosofía de Hegel; no se ha medido realmente con ella, como lo hizo Feuerbach -y, una vez más, no sabríamos reprochárselo. Pero entonces cesemos de tomar como una crítica filosófica de Hegel una rapsodia de impresiones de lectura diagonal. Que Marx piense y escriba en el universo discursivo hegeliano (cosa que el Sr. Althusser tiende a minimizar demasiado), es una cosa completamente distinta -completamente distinta, por ejemplo, de la relación auténticamente crítica de Leibniz con Descares o de Hegel con Kant.

31 Que sean de nuestro conocimiento, los mejores bosquejos de esta investigación hasta este momento se encuentran en los trabajos del Sr. Giannotti, ¿no será porque es uno de los raros marxólogos que no se contenta con un retrato-robot escolar de Hegel? Es verdad que estos trabajos parecen cada vez más llevar a su autor hacia una «ontología de lo social», y no hacia un análisis de las «interpretaciones» marxianas. Si acaso él encuentra ésta incompatible con aquella, que nos disculpe por esta elogiosa cita.

32 Castoriadis: Expérience du mouvement ouvrier. Op. cit., p. 60.
} 
resultar útil el «contra-movimiento» que designa Nietzsche con la palabra Superhombre, permitiéndonos quizá determinar mejor el «viejo ideal» que continuaría propagándose a través del marxismo.

\section{El superhombre, un tipo de hombre y no de «humanidad»}

«Contra-movimiento», ¿qué quiere esto decir? Nietzsche, observa Heidegger, no espera una «evolución de la humanidad» ni el advenimiento de una clase universal. El humanismo que creó «no tiene su estructura esencial ni en el individuo ni en la masa, sino en el tipo... En el pensamiento nietzscheano del Superhombre, no se trata de un tipo de hombre en particular, sino por primera vez del ser humano que

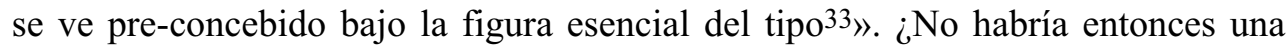
diferencia de naturaleza entre esta soberanía del tipo (de un cierto «tipo de hombre») y los ideales de dominación humanistas, herederos de la Aufklärung, que Heidegger acaba de evocar en la página precedente? Heidegger, ciertamente, niega esta eventualidad: para él, la «soberanía sobre el planeta entero» de la que habla Nietzsche no puede ser más que una variante de la mitología del progreso. Nietzsche parece sin embargo evitar esta interpretación cuando pide que no se entienda por Superhombre «el tipo idealista de una especie de hombre superior 34 »). El Superhombre se opone expresamente a todo ideal de Menschheit, y en particular al ideal post-hegeliano de «el hombre genérico». «Nicht Menschheit, sondern Uebermensch ist das Ziel $35_{\text {». }}$ Y, desde las Intempestivas, en el homenaje de despedida que le dedica a Wagner, Nietzsche subraya ya hasta qué punto «la raza futura», de la cual el artista es profeta, no debe ser entendida como una esencia normativa de lo humano, como se entendía hasta este momento:

Que la sana razón nos preserve de creer que la humanidad deba nunca descubrir las reglas ideales y definitivas, y que la felicidad deba brillar siempre en un resplandor siempre igual, como el sol de los trópicos, sobre los hombres sometidos a estas reglas. Wagner no tiene nada en común con una creencia tal, no tiene nada de utopista.

No pensemos esta «raza futura» en relación con nosotros, ni en sentido comparativo ni en sentido superlativo. «Puede ser incluso que esta raza futura parezca peor que la presente, ya que será más franca tanto en el bien como en el mal ${ }^{36 . » ~ E l ~}$

\footnotetext{
33 Heidegger: Nietzsche. Tome II. Paris: Gallimard, 1972. p. 117-118

34 Nietzsche: Ecce homo. Kröner. Bd. VIII, S. 338.

35 Wille zur Macht, $\mathrm{n}^{\circ} 1001$.

${ }^{36}$ Quatrième Consideration intempestive. Kröner. Bd. II, S. 384. Trad. G. Bianquis. Paris: Aubier, 1954. p. 294.
} 
Superhombre no podría por tanto hacer de «fin último» de nuestro proceso histórico. No podría ser el tema de una predicación: «Las aspiraciones hacia lo alto no son las nuestras ${ }^{37 . » ~ E l ~ m e r o ~ h e c h o ~ d e ~ d e s i g n a r l o ~ c o m o ~ e l ~ t e ́ r m i n o ~ d e ~ u n ~ e s f u e r z o ~ p a r a ~}$ el que los hombres de hoy serían colectivamente capaces prueba que aún no hemos destruido el molde de los antiguos «ideales», y que no hemos renunciado a imponer un sentido a la Historia. He aquí porqué el Zaratustra comienza con un fracaso pedagógico: era un error querer movilizar al pueblo, hacer del pueblo un agitador, como si la llegada del superhombre fuera un objetivo que puede perseguirse -como si la masa no fuera a entender por Superhombre otro «tipo ideal de humanidad». Para imaginar que el Superhombre está al alcance de la humanidad actual, hay que continuar deseando el porvenir de la misma manera en que los cristianos desean el reino de Dios, ya que no se trata de un individuo cualquiera el que necesita una idea del «porvenir humano» para poder vivir, se trata por el contrario de un individuo ya debilitado, ya «mediocrizado». Importa muy poco, por tanto, que el «ideal» cese de ser una quimera en nuestra cabeza para ser presentado como el movimiento de fondo que anima efectivamente la historia... Dónde esta la diferencia con la utopía, dado que, también aquí, «creemos saber lo que es deseable en última instancia relativamente al hombre ideal». Laicos o religiosos, idealistas o «científicos», las largas marchas hacia el universal concreto se parecen demasiado para no responder al estímulo de la misma debilidad 38 . Por tanto, hay que renunciar a toda pedagogía en el sentido tradicional: «Yo no hablaría ya ni siquiera al pueblo; es la última vez que pronuncio una palabra... Es a los solitarios a los que dirigiré mi canto.» Ya no puede

\footnotetext{
37 Wille zur Macht, no 993.

38 «Esta creencia no es más que la consecuencia de una larga permanencia en el ideal cristiano: es éste el que retomará muy rápido el examen del "tipo ideal". Creemos: 1. saber que es deseable aproximarse a un tipo único - 2. saber de qué especie es este tipo - 3. saber que todo desvío en relación con él es una regresión, un retraso, una pérdida de fuerza y de poder para el hombre... Soñar las condiciones en que este hombre realizado sería mayoría: nuestros socialistas nunca han estado más allá, y tampoco siquiera los señores utilitaristas. Por tanto, una finalidad parece regir la evolución de la humanidad: en todo caso, la creencia en un progreso hacia el ideal es la única manera bajo la cual es pensada en nuestros días una especie de finalidad para la historia de la humanidad. In summa: la llegada del reino de Dios, la hemos desplazado al futuro, en la tierra, en la humanidad - pero, en el fondo, mantenemos firme la creencia en el viejo ideal.» (Wille zur Macht, $n^{\circ}$ 339). Releamos, a la luz de esta indicación de Nietzsche, algunos textos marxistas que se presentan a menudo como testigos del anclaje del marxismo en la realidad histórica, en lo «concreto», al contrario del utopismo. Bajo la tapadera de «la Historia» la escatología aparece en ellos a cielo abierto. De ahí el pasaje de la Santa Familia que el Sr. Dangeville (Op. cit., p. 31) juzga «quizás brutal, pero claro». «Lo que importa, es que cada proletario es lo que debe hacer históricamente, conformemente a su naturaleza: su finalidad y su acción históricas le son trazadas de manera tangible e irrevocable tanto en su situación existencial como en la organización de toda la actual sociedad burguesa. El proletariado ejecuta el juicio que, a través de la producción del proletariado, la propiedad privada burguesa pronuncia contra sí misma.» Efectivamente, el texto es «claro»...
} 
tratarse de designar a los hombres el porvenir del que son portadores 39 . Debemos osar decirles, al contrario, que jamás hubo humanidad, sino, bajo este nombre, hundimiento creciente de las fuerzas, que compensó la formación de un mito: «la especie humana» como ser colectivo investido de una misión. Y las ideas recibidas de maduración de la historia, de evolución, de proceso no son más que las figuras de esta afabulación mórbida. Otra de tantas variaciones que tocan [jouent] «los doctores de la finalidad de la existencia» sobre el tema de la realización de la humanidad. Otra de tantas fintas a la única cuestión pedagógica seria: ¿qué tipo de hombre debemos querer? Cuestión radicalmente nueva esta, puesto que ya no trata de aportar a los hombres el universal que les habría sido ocultado o injustamente escondido; no prolonga el Discurso sobre la inigualdad; no desemboca en una nueva «finalidad de la existencia», sino en una nueva manera de hacer la pregunta Wozu? ¿Para qué?

La novedad de esta problemática, se percibe particularmente bien en el primer aforismo de la Gaya ciencia. Hasta ahora, dice Nietzsche, nadie ha osado «desvelar la comedia de la existencia». Nadie ha osado representarte «en tu miseria de mosca y de rana». Y es que «los doctores de la finalidad de la existencia» no quieren de ninguna manera que «nos riamos de la existencia y de nosotros mismos». También proponen al individuo un fin que, efectivamente, lo vuelve "por un tiempo interesante a sus propios ojos» - si bien los hombres tienen en adelante necesidad de esta «confianza periódica en la vida» que les es infundida. «De vez en cuando, el hombre debe creer que sabe porqué existe...». Pero, en realidad, de espaldas a todos - tanto doctores como discípulos - lo único que se protege es el interés de la especie, la garantía de que la supervivencia de la especie prosiga ${ }^{40}$. Tampoco resulta sorprendente que lo que entendemos, desde Kant y Fichte ${ }^{41}$, por «destino»

39 Ver Nietzsche: L'antéchrist. § 4, y el final de la segunda Disertación de la Genealogía de la moral: «¿Elevamos aquí un ideal, o lo invertimos? - se me preguntará. ¿Pero no os habéis preguntado vosotros mismos bajo qué precio ha sido posible la edificación de todo ideal en este mundo?»

40 Ciertamente, Nietzsche presenta al socialismo como la última aspiración de los individuos debilitados por la decadencia, el ideal de los «individuos fugitivos que quieren conquistar su felicidad a través de la socialización». ¿Pero de qué vale este «individualismo»? «El egoísmo es aún extremadamente débil... Ellos no piensan más que en sí mismos, pero en si-mismos en la medida en que el ego se encuentra desarrollado por el afecto formador de rebaño.» (Fragmentos inéditos de la época de la Gaya ciencia. Trad. Klossowski. Paris: Gallimard, 1967. p. 399.)

41 Ver la descripción que hace Fichte de aquella sociedad de la que será excluida toda división propia de las «intenciones egoístas» y que realizará «la finalidad de nuestra vida terrestre». Una comunidad tal que «ya no es posible utilizar la libertad para hacer el mal. Es necesario que el hombre decida o bien renunciar enteramente a su libertad y volverse sin refunfuñar una pieza pasiva en el mecanismo del conjunto, o bien aplicar esta libertad al bien... La lucha del bien contra el mal queda (por tanto) suprimida, pues en conclusión ya no puede haber mal». (La destination de l'homme. Trad. J. Molitor. 1942. p. 233 sq.). Sobre las nociones de Bestimmung y de Beruf en Fichte, ver el comentario del Sr. Viellard-Baron a su traducción de las Conférences sur la destination du savant. Paris: Vrin, 1969. p. 94 sq. 
o «vocación» de la humanidad (Bestimmung, Beruf) deba llevarse a cabo bajo la forma de una gregarización, de una inserción tan perfecta del individuo en la especie que prevendría para siempre crisis y tensiones. Si las escatologías del idealismo alemán convergen en este punto, si van dirigidas hacia la situación inmejorable de una socialización consumada que prohibiría para siempre todos los Pólemos, es porque están al servicio de una «forma de vida» determinada, aquella de la que «nuestros socialistas», tomando el relevo de la filosofía, se hacen defensores. Dejando de lado las diferencias doctrinales, toman la misma opción interpretativa sobre la civilización; ambicionan la dirección de la misma decadencia. Los «socialistas» pueden prometer una mutación del hombre sin precedentes, pero no hacen más que inventar otra «finalidad de la existencia», la última quizá a la que se sumará nuestra «civilización» desesperada. Es por lo tanto previsible que estos «realizadores» de la filosofía, lejos de evadirse del modelo tradicional de cría del hombre, no harán más que agravarlo. Por debajo de su trabajo de topo hoy, y mañana a través del Estado tiránico que edificarán, está el Erziehung escatológico que continúa su ruta y logra su última prórroga. «La llegada de la plebe significa una vez más la llegada de los valores antiguos ${ }^{42 . »}$

Es cierto que Nietzsche no menciona nunca el nombre de Marx, pero este silencio no debe hacer augurar que Marx no entraría dentro de su tipología de «socialismo». Todo indica, por el contrario, que el marxismo es justiciable de la contra-escatología nietzscheana, en la medida en que se mantiene en resonancia con la mitología espontánea del siglo XIX y se transmiten en ella las filosofías del porvenir que Nietzsche incluye entre los productos de la «decadencia». Aún hoy, ¿no se ajustan perfectamente los temas que acarrea a los montajes interpretativos que nos son familiares? Tómense los temas de «humanidad reconciliada», de «abolición de clases» de «historia educadora», etc.: estamos al mismo nivel, se combinan tremendamente bien con las asociaciones que, desde el colegio, pone en marcha en nosotros la palabra «historia». No nos desconciertan. Cuando Marx enumera los títulos civilizadores del capitalismo, puede dejarnos perplejos, pero no desorientados. O mejor, retómese la página truculenta de Engels sobre la esclavitud antigua ${ }^{43}$; medítese con él acerca de este progreso que fue la esclavitud «incluso para los esclavos» (¿qué sabe él de eso?) y recórrase de nuevo la sorprendente conexión que nos propone: $\sin$ la esclavitud antigua, no habría ni arte, ni ciencia griega, ni Imperio romano; por lo tanto, «tampoco Europa moderna»; por lo tanto, «tampoco socialismo moderno». En este caso sí que quedaremos desconcertados, y pensaremos con alivio que nos libramos de una buena el día que Espartaco fue capturado; pero conozco a pocas personas que se partirían de risa... Que la historia es una ruda educación, lo sabe-

42 Wille zur Macht, $\mathrm{n}^{\mathrm{o}} 864$.

${ }^{43}$ L'anti-Dühring. Ver Engels. Rôle de la violence dans l'histoire. Trad. E. Bottigelli. Éd. Sociales, 1977. p. 31-33. 
mos («lo creemos saber») al menos desde Hegel, que había abierto la vía con su serena apología de la represión cristiana en la Edad Media. Tras él, los descubrimientos científicos se suceden («a pasos de gigante», por supuesto). 1810: descubrimiento de la liberación de la humanidad «por la servidumbre». 1848: descubrimiento de la liberación de la humanidad por el desarrollo del mercado mundial. 1878: descubrimiento del papel de la esclavitud antigua... Esclavitud, servidumbre, trata de Negros, sin duda la factura fue coqueta y los viernes santos no fueron solamente especulativos, ¿pero no se trata a fin de cuentas de la gran liberación final? Paciencia: «El enorme crecimiento de las fuerzas productivas» hará superflua a «toda clase dominante y explotadora». Podemos burlarnos de este desciframiento escatológico de café de Comercio cuando aparece demasiado claramente y no está suficientemente enmascarado por su jerga, pero estaremos de acuerdo en que raramente nos enfurece; estaremos de acuerdo en que nunca nos produce nauseas. Es quizá porque los virus cristianos del «sufrimiento redentor» y de la felix culpa nos han sido transmitidos por sangre demasiado bien... Pero qué más da. Recibidas estas ideas, en todo caso, nuestro «sentido común» las traga como si fuesen hostias. Son indispensables, según parece, para todo proyecto revolucionario; están integradas en el «humanismo». No pretendemos decir que el marxismo se reduce a estas pamplinas. ¿Pero cómo no acusarle hoy en día de ser el principal responsable de su supervivencia y difusión? ¿Se ve ahora lo que teníamos en mente al hablar de Nietzsche como de un «analizador»?

Otro tema optimista y «humanista» que retoma, sin desconcertarnos, la literatura marxista: el de la pertenencia esencial del individuo humano a la especie. La «evidencia» de que la vida individual es un modo de vida genérico, de que el individuo no es más que un «ser genérico determinado» está sellada en el zócalo del marxismo. Es incluso indispensable para la definición de la conciencia como expresión teórica de «aquello de lo cual la comunidad real, la organización social, es la forma viviente ${ }^{44}$ ». Y, también ahí, a través de la noción hegeliana de género (Gattung) se nos remite a una concepción bien determinada de lo que debe ser la «formación» del hombre: en la línea de Hegel, esta «formación» no podrá ser más que un «allanamiento» (Glättung), un borrado de las diferencias que separan a los individuos, esos átomos turbulentos siempre rebeldes a la buena totalización ética. Esta «interpretación» universalista está presente desde el principio en Marx: el crimen por excelencia de la explotación es, como sabemos, que le ha arrancado al hombre su vida genérica ${ }^{45}$. ¿Se me hará acaso ver que resulta deshonesto servirse sólo de estos textos de 1844 ? Pero yo no conozco textos ulteriores en los que la liberación del individuo se encontrara separada de su realización genérica: es siempre la integración de la especie, la asimilación, lo que será tomado como positivo, y el

44 Marx: Manuscrits de 1844. Trad. Bottigelli. Éd. Sociales, 1972. p. 90.

45 Ibid. p. 61-64. 
tema de la diferencia será relegado a lo negativo (atomización, división, desequilibrio, inigualdad). Qué raro es este materialismo post-hegeliano, digámoslo de paso: en efecto, se trata de un curioso materialismo que sospecha de lo individual, es decir, de aquello a lo cual otros materialistas (epicúreos, estoicos) habían sabido darle un status positivo contra Platón y Aristóteles, contra los filósofos del Logos ${ }^{46}$. Pero así es: pensamiento post-hegeliano, el marxismo nos ha acostumbrado a la idea -que nos parece irrecusable- de que, en la explotación, es su Menschheit lo que es robado al explotado. Ahora bien, es suficiente devolver la palabra al léxico neohegeliano para darse cuenta de todo lo que implica esta aserción socio-ontológica: que toda lucha eficaz debe ser tomada en el nombre de una norma universal. Y el lector sabe el resto: que una clase no menos universal, o la vanguardia que se beneficiará de esta universalidad por procuración, se verán necesariamente forzadas a poner en juego esta norma y a hacerla respetar. Es, por tanto, de forma totalmente natural que el funcionario hegeliano retoma el servicio y, hasta la abolición de clases, tiene unos bellos días frente a sí. Importa mucho que la opresión, la miseria y el hambre sean interpretados con ayuda de evaluaciones salidas de Hegel, -que se hable del explotado como «particularizado», arrojado a la «inmediatez». No se trata de una reivindicación revolucionaria cualquiera la que nazca de la elección de este pathos. Son «ideales» muy marcados los que lo influirán. Y sería útil tomar conciencia de ellos.

Pero es cierto que esto no preocupaba lo más mínimo a Marx. Cuando uno ha leído El Único y su propiedad de Stirner, no hay nada que haga menos gracia que las pullas disparadas a «Sancho» en La Ideología alemana. Marx se burlaba de Stirner por haber permanecido en la desmitificación - bien cómoda - de lo «sagrado», y en la crítica de los «ideales». Ciertamente, Stirner no tenía nada de pensador político. Pero cuando denuncia las entidades post-hegelianas de hombre y de humanidad, tiene por lo menos el mérito de sospechar de las valoraciones que el marxismo hereda cándidamente («El hombre es el capital más precioso»); tiene por lo menos el mérito de formular - torpemente, coléricamente - la necesidad de terminar

\footnotetext{
46 Por supuesto, nadie tiene el copyright de la palabra «materialismo». Pero actualmente el sentido más útil de esta palabra es sin duda el que el Sr. Deleuze emplea en la Logique du sens (Paris: Minuit, 1969), partiendo de los estoicos y de los epicúreos (ver el estudio sobre Lucrecio y el simulacro): pensamiento del acontecimiento de la superficie, expulsión de todo esencialismo... A la luz del materialismo antiguo, nos damos cuenta de lo vacía e insulsa que resulta la oposición «materialismo/idealismo», - y también de lo nociva que es, sugiriendo seguidamente que fuera de la torpe gnoseología de Lenin, no habría lugar más que para la metafísica de los «perros guardianes». La tarea más urgente de un pensamiento liberador, por lo tanto materialista, es restaurar el materialismo en su verdad de polémica contra el logocentrismo, contra la ontología aristotélica (en la que supo acomodarse tan bien el «materialismo» post-hegeliano). Lucrecio para curar de la dialéctica, Crisipo para curar del eidos... De forma que un curso de filosofía antigua puede estar, sin que lo parezca, al servicio de un proyecto eminentemente político.
} 
con la Menschheit, de hacer morir al «Hombre». Y, como decía alguien que fue mezclado contra su voluntad en este cómico asunto criminal, no es vuestro «Hombre total» del porvenir lo que nos interesa, vuestro «héroe positivo», vuestro «viejo-decorado» de la desalienización, sino saber, por ejemplo, de qué categorías médico-legales sería justiciable, si se le permitirá ser «perverso» y qué sistema penitenciario y psiquiátrico se reservará al «capital más precioso». Sí, nada más que estos pequeños detalles, pero que son suficientes para traducir nuestra desconfianza hacia el peligrosamente abstracto «hombre total», del que el Superhombre - aún mejor que el Único - fue justamente la expresa y sistemática transgresión.

\section{Domesticación o cría*}

El Superhombre, como hemos visto, no es el término de una larga marcha de la humanidad. Designa más bien al vacio en el que estaremos seguros de no dejarnos pillar [piéger] por palabras como «humanidad», lentamente impregnadas de la decadencia occidental. Vivir bajo el horizonte de lo superhumano, es, por lo menos, tratar de eliminar las falsas evidencias de una cultura que no puede ser, cada vez más, otra cosa que sinónimo de domesticación, y cuya salvaguarda, piensa Nietzsche, es el objetivo común de todas las corrientes de «ideas modernas». Ya que sería falso creer que el ideal de domesticación se va borrando con las doctrinas «iluminadas» de la educación o del progreso del género humano: Nietzsche presintió lo que demuestra Foucault en Vigilar y castigar. Ciertamente, no se presenta la transformación del hombre como una formación destinada a producir individuos conformes al tipo deseado por el formador. Pero, a medida que declinan los viejos ideales teleológicos de heteronomía, la especie se va haciendo abiertamente el más exigente y meticuloso de los criadores. Ciertamente, no se trata de un ser tiranizado y atontado lo que fabricamos en su nombre, sino de un ejemplar corriente, sociable, y por lo tanto obediente - y cuanto más normal encuentra el individuo ser regido por los intereses de la especie, cuanto más útil encuentra ser utilizado por ella, más se degrada en un ejemplar corriente. Es su destino en tanto que ser racional. Kant lo proclama:

En el hombre (como único ser racional sobre la tierra), las disposiciones naturales destinadas al uso de la razón debían desarrollarse enteramente sólo en la especie, y no en el individuo 47 .

\footnotetext{
* En francés «Domestication» (traducción de «Zähmung ») y «Dressage» (traducción de Züchtung). A este respecto, ver nota 48. N. del T.

${ }^{47}$ Kant: Idée d'une histoire universelle au point de vue cosmopolitique. Deuxième proposition.
} 
Por consiguiente, la opción vital parece clara: o bien la dispersión de los «egoísmos», la caída en la «animalidad» o bien el devenir-genérico (traduzcamos: la aceptación de la degeneración). Y, de esta domesticación, Kant da fórmulas tan brutales como las de Nietzsche:

Las ciencias y las artes contribuyen a que el hombre resista menos. No es que se vuelva mejor por esa vía, sino más dócil... Se hace propiamente más débil, ya que cada necesidad es una lazo que lo ata a las leyes, incluso si éstas son arbitrarias ${ }^{48}$.

¿Pero por qué remontarnos hasta el idealismo? «Animalidad», «egoísmo», son también las evaluaciones negativas de los «socialistas». Asumen tan bien el ideal de domesticación por la especie que ellos tampoco consideran la eventualidad de otro modo de disciplina - de una cría ${ }^{49}$, cuyo éxito sería medido por la amplitud de lo instintivo que el individuo sería capaz de dominar por su cuenta, sin deber reprimirlo (en tanto que ser-genérico). Nietzsche llama Superhombre al resultado de esta formación inédita: he ahí la única verdadera bifurcación pedagógica. Se comprende por tanto que el superhombre designa antes de nada el retroceso a llevar a cabo en relación con la hipócrita tradición que nos rodea -en el corazón de la cual, sin que esto nos sorprenda, la reivindicación revolucionaria fue expresada en el mismo lenguaje que la domesticación universalista. El superhombre no es un «ideal» edificante, sino el reglaje gracias al cual podríamos emprender la filología de esta tradición, determinar la tasa de polución de «el aire que respiramos» - por retomar las palabras de Sartre.

Dicho esto, podemos afirmar que Nietzsche no hace más que oponer una visión [phantasme] a las visiones de futuro de sus contemporáneos. Quizá para hacer menos desconcertante esta visión, se ha querido ver en el superhombre una lejana prefiguración de la «era de los organizadores» de Burnham. De nuevo, es mucho decir. Más valdría preguntarse en primer lugar de dónde viene nuestro desasosiego frente a las presentaciones que nos ofrece Nietzsche del superhombre. Efectivamente, ese desasosiego viene, ante todo, del hecho de que nos gustaría,

\footnotetext{
48 Kant: Akademische-Ausgabe. Tome XIX. Réflexion $\mathrm{n}^{\circ} 6583$.

49 Ver Troisième consideration intempestive. Kröner. Bd. II, S. 250-252. «Desde siempre, los sacerdotes han querido mejorar. Pero nosotros reiríamos si un domador nos hablara de la mejora de sus animales. En el mejor de los casos, la domesticación de la bestia no se logra más que en prejuicio suyo: en el mismo sentido, el hombre moral no es un hombre mejor, sino un hombre debilitado. Pero resulta menos nocivo...» (Wille zur Macht, $\mathrm{n}^{\circ}$ 397) - «Lo que me gustaría dejar claro con todas mis fuerzas es que no hay una confusión peor que la que se comete entre los términos domesticación (Zähmung) y cría (Züchtung). La cría, como yo la entiendo, es un medio de enorme acumulación de fuerzas de la humanidad, de forma que las generaciones puedan continuar construyendo partiendo de aquellas que las precedieron - creciendo a partir de ellas, haciéndose más fuertes no sólo exteriormente sino interiormente, orgánicamente...» (Ibid., n³98).
} 
entre otras cosas, ver ahí descifrado nuestro porvenir, una prospectiva en competencia con otros. Sin embargo, con Nietzsche, como hemos visto, se trata de algo muy distinto. El Superhombre no es un destino probable para este tipo de porvenir, que, a ojos de Nietzsche, carece de interés. En efecto, la «civilización» ha cavado tan bien su lecho que, en lo esencial, el contenido de nuestro «porvenir» prácticamente se ha detenido. Crecimiento, mutaciones tecnológicas, avalancha demográfica determinan en general lo que será. ¿Quiénes serán los gestores más competentes? ¿Dónde estarán los técnicos más capaces de inventar y de instaurar los equilibrios sociales más tolerables, más duraderos? Preguntas sin duda primordiales para los explotados y sobre todo para los hambrientos. Sí, sin duda... Pero Nietzsche nos advierte: estas soluciones diversas, provenientes del mismo crisol, no afectarán nunca más que el ángulo de inclinación de la pendiente. Nadie sabría detener la decadencia. Y como «nuestros socialistas» están ciegos ante esta fatalidad, sus predicciones no pueden ser (no podían ser) más que irrisorias. Consúltese a Engels a este respecto: «El enorme crecimiento de las fuerzas productivas alcanzado en la gran industria» permitirá una repartición racional del trabajo tal que todos estarán en disposición de participar en «los asuntos generales de la sociedad - tanto teóricos como prácticos». Pero ¿cuál sería el rostro de esta cultura tan generosamente abierta? ¿Cómo imaginarla? ¿Cómo imaginar la cultura que será fomentada por la racionalidad tecno-burocrática? ¿Cómo no presentir más bien el frenesí de la consumición, la rescisión de la vida privada, al abrigo del Estado totalitario? ¿Qué milagro hará que los hombres eviten este destino mientras no sea puesta en cuestión su relación con la institución, el trabajo, la comunicación? ¿Cómo evitarán este destino mientras que le escuela, por no poner más que un ejemplo, les inculque, bajo todas las latitudes, la obediencia a una autoridad universal?

Ciertamente, no es imposible la llegada de una cultura superior en las condiciones materiales que Engels prevé: Nietzsche está de acuerdo con esto. Pero el desarrollo de esta cultura requiere una ruptura con la «civilización» de la domesticación. Una ruptura que el «socialismo» no tiene en absoluto la capacidad de efectuar, ya que su práctica no tiene sentido si no es relativamente a los significados que proyectan la sociedad que él critica y el tipo de poder que él pretende ejercer $a$ su vez... Me parece que es en los alrededores de esta idea (que retoma hoy el Sr. Castoriadis) donde hay que tratar de comprender el «aristocracismo» de Nietzsche. Significaría por tanto que, en lo que respecta a la Bildung, de nada sirve subvertir la organización social, si no educamos (o no dejamos educarse) a otra humanidad, otra «raza».

Llega un momento en el que el hombre tiene un excedente de fuerza a su servicio: la ciencia conduce a esta esclavitud de la naturaleza. El hombre se beneficia entonces del ocio: para formarse y hacerse algo nuevo, algo más alto. Nueva aristocracia ${ }^{50}$.

50 Wille zur Macht, $\mathrm{n}^{\circ} 953$. 
¿De dónde podrían venir estos excedentes, estos aristócratas lo suficientemente libres como para desvincularse de la decadencia? Con total seguridad, del exceso mismo de la decadencia. Es la única respuesta posible. Y es por eso que los «espíritus libres» deben ser los últimos en querer detener la decadencia. «La igualación del hombre moderno es el gran progreso que no podemos detener; deberíamos acelerarlo aún más ${ }^{51}$.» ¿Hasta la llegada del socialismo? ¿Por qué no? No es imposible que el socialismo sea el administrador más eficaz de los termiteros por venir. Las experiencias socialistas serán incluso indispensables: sólo al haberlas atravesado nos convenceremos de que nuestra «civilización», decididamente, no ofrece más recursos políticos contra el envilecimiento. Sólo cuando, contra todo pronóstico, «la voz ronca» del socialismo haya «retomado el grito de guerra: el máximo de Estado posible» explotará «con mucha más energía el grito de adhesión opuesto: el mínimo estado posible $52 》$ y «los nuevos bárbaros» se pondrán en marcha. Si el ascenso del «socialismo» es deseable, es porque acelerará prodigiosamente la «decadencia»: «las mismas condiciones que desarrollan el envilecimiento del rebaño desarrollan también al conductor de animales ${ }^{53}$.»

Reencontramos ahí un esquema bien conocido: la salud no surge más que en el punto de extrema miseria. Es posible que, por este rasgo, Nietzsche pague su tributo al siglo XIX. Pero es todo lo que le concede: por lo demás, el Superhombre mantiene su anonimato. ¿Se tratará de una casta de ingenieros prometeicos consagrada a la explotación planetaria? No lo parece, incluso si el reino del superhombre exige que la ciencia se haya vuelto la principal fuerza productiva: la única tarea del Superhombre, es esculpirse a sí mismo. ¿Clase de ociosos, entonces, a imagen y semejanza de los Maestros hegelianos? Tampoco: mientras que el Maestro hegeliano perdía su alma en la consumición, el Superhombre no tendrá nada de aprovechado: «Hombres de aumento, sustentados por el sobretrabajo universal», forman una casta «más pobre, más simple, y sin embargo poseedora de poder ${ }^{54 . » ~ ¿ D o m i n a-~}$ dores? No es tan simple. «No solamente una raza de señores cuya tarea se limitaría a gobernar, sino una raza dotada de una esfera vital propia, con un aumento de fuerza por la belleza, el coraje, la cultura ${ }^{55}$...» Por otro lado, Nietzsche los dispensa incluso del mando, indigno de sus cuidados: «Más allá de los que reinan, desatados de todas las ataduras, viven los hombres superiores; y los que reinan son sus instrumentos $56 . »$

La aparente utopía se transforma en enigma para quien quisiera adivinar qué era el ideal de Nietzsche. Pero el que quisiera hacer esto estaría cometiendo ya un con-

51 Ibid., n ${ }^{0} 898$.

52 Nietzsche: Humain trop humain. I, §479.

53 Wille zur Macht, $\mathrm{n}^{\circ} 868$, ver $\mathrm{n}^{\circ} 898$.

54 Ibid., $\mathrm{n}^{\mathrm{o}} 764$.

55 Ibid., $\mathrm{n}^{\mathrm{o}} 898$.

56 Ibid., $\mathrm{n}^{\circ} 998$. 
trasentido: ¿qué interés podría tener aquí un «ideal» que dependería de nuestra tipología política corriente? «No sois vosotros, hombres supersticiosos, lo que esperaba sobre estas montañas», dice Zarathoustra a los reyes al final del libro. No son tampoco, ni mucho menos, los «managers» o los señores de la guerra, - ninguno de los que se encargarían de planificar la ciudad futura, de volver a poner en marcha el aparato de Estado. Si queremos a cualquier precio un modelo de estos «excedentarios» 128 tan difíciles de imaginar, vayamos más bien a las páginas de la Política (III, 13) que Aristóteles consagra al ostracismo: hay seres demasiado superiores como para que una polis [cualquier polis] pueda someterlos a sus reglas; sería como sí, añade Aristóteles, «pretendiéramos compartir con Zeus el gobierno del mundo». La parábola del Superhombre fue escrita en el margen de textos antiguos; es el otium nobiliario lo que invoca. Y basta con seguir la huella del «viejo filólogo» (tomando sobre todo como guía el escrito Homero Wettkampf) para que la imagen [phantasme] del Superhombre se vuelva sencillamente la invitación a un desplazamiento, a un exilio sistemático que nos haría excluir sistemáticamente nuestras evaluaciones presentes. Si el Superhombre no es, sobretodo no es, otro «tipo ideal de humanidad», no puede más que iniciar una cura de nihilismo salubre. Fantasía [phantasme] si se quiere, pero una fantasía encargada de conjurar las fantasías -más insidiosas- que nos modelan.

Un poder que no se ejercería más por medio de un aparato represivo, un dominio de sí que no pasaría más por una sumisión al universal: son estos los conceptos que focaliza el Superhombre; por supuesto, es fácil de relegar, con un encogimiento de hombros, al utopismo - si, tan sólo preocupados por la «marcha de la Historia», nos mantuviéramos sordos y ciegos ante la forma en que se mueve el mundo a nuestro alrededor y al nacimiento de evidencias que habrían sido inimaginables, hace sólo veinte años. Sistema penitenciario, sistema escolar, servicio militar, jerarquía burocrática, familia falocrática: no ha hecho falta, después de todo, más que una generación para que oigamos reventarse tantas instituciones durante tanto tiempo incuestionables... Olvídense por tanto de la historia mesiánica que les es tan querida; piensen en términos de generaciones más que de clases; en suma, dejen el siglo XIX por un momento - y admiren cuánto trabaja hoy en día en la superficie el joven topo. Por todas partes, a nuestro alrededor, nace una nueva Erziehung - e incluso a través de la «Lotería deportiva», para quien tiene orejas. Nunca ha sido menos quimérico imaginar la formación de otro tipo de hombre, porque jamás ha sido tan visible que la única «política» digna de interés pasa por la educación - y más exactamente por esta forma apasionante de autoeducación, que llamamos a la ligera (para acercarla más a algunos mitos familiares: «la revuelta», «el anarquismo») polémica [contestation].

Ciertamente, podemos elegir retener de la parábola de Nierzsche tan sólo su rasgo más desagradable y menos desconcertante: la certeza de que la explotación 
no terminará jamás, de que toda cultura existe al precio de una jerarquía, de una Rangordnung. Pero sabemos hasta qué punto Nietzsche se rebela en Ecce homo contra esta interpretación: «¿Será posible que la Gaceta nacional, un periódico prusiano... haya llegado hasta el punto de interpretar mi obra como un signo de los tiempos, como la verdadera filosofía de los hidalgos de aldea». Hemos tratado aquí de tener en cuenta esta advertencia, y de preguntarnos si el interés que suscita Nietzsche hoy en día no sería el indicio de que la originalidad de su cuestionamiento político comienza por fin a hacerse perceptible. Utilizando la idea de Superhombre no como punto de mira, sino como compás, hemos querido sugerir también, a título de ejercicio, que no procede modificar, a propósito del marxismo, el diagnóstico que hace Nietzsche de «nuestros socialistas». Heredero, tanto como cualquier otro «socialismo», de la tradición universalista, el marxismo no pretende jamás poner en tela de juicio las reglas del juego de una «civilización» cuyo hundimiento percibe Nietzsche y, por ello, hipotecó pesadamente el lenguaje revolucionario de nuestro tiempo, lo cuajó en su «lenguaje estereotipado». Por consiguiente, utilizar a Nietzsche con el fin de hacer salir de debajo de la vieja creencia las valoraciones caducas que han atrapado siempre a sus adeptos, no es consagrarse a la desenvoltura del renegado; sospechar que el destino trágico del marxismo occidental no se debe tanto a las condiciones históricas de la historia de Rusia cuanto a que estaba inscrito en los prejuicios de sus fundadores, no es tomar el camino monótono del cinismo y de la negación. No es más que negar el siglo XIX. - Y aquí creemos oír a Nietzsche interpelándonos: «¿No va siendo ya hora, amigos míos?».

Traducción de Víctor García Cruz 